\title{
A Novel Unified Approach to Predict Human Hepatic Clearance for Both Enzyme- and Transporter-Mediated Mechanisms Using Suspended Human Hepatocytes
}

\author{
Keith A. Riccardi, David A. Tess, Jian Lin, Roshan Patel, Sangwoo Ryu, Karen Atkinson, \\ $\mathrm{Li} \mathrm{Di}$, and Rui Li
}

Pharmacokinetics, Dynamics and Metabolism, Medicine Design, Pfizer Worldwide R\&D, Groton, Connecticut (K.A.R., J.L., R.P., S.R., K.A., L.D.) and Systems Modeling and Simulation, Medicine Design, Pfizer Worldwide R\&D, Cambridge, Massachusetts (D.A.T., R.L.)

Received November 24, 2018; accepted February 5, 2019

\section{ABSTRACT}

The accurate prediction of human pharmacokinetics is critically important in modern drug discovery since it drives both pharmacological and toxicological effects. Although significant progress has been made in predicting drug disposition by hepatic drugmetabolizing enzymes, predicting transporter-mediated clearance is still highly uncertain. Furthermore, different approaches are often used to predict clearance with and without transporter involvement, hence the major clearance pathway for a compound must first be determined to know which approach to use. As a result of these challenges, a novel unified method has been developed using cryopreserved suspended human hepatocytes to predict human hepatic clearance for both enzyme- and transporter-mediated mechanisms. This method hypothesizes that, once in vitro metabolic stability is scaled by partition coefficients between hepatocytes and buffer with $4 \%$ bovine serum albumin, in vivo clearance can be better predicted. With this method, good in vitro-in vivo correlation of human hepatic clearance has been obtained for a set of 32 structurally diverse compounds, including such transporters as organic anion-transporting polypeptide substrates. The clearance predictions for most compounds are within 3-fold of observed values. This is the first time that multiple compounds result in good in vitro-in vivo extrapolation using an entirely "bottom-up" approach without any empirical scaling factor when transportermediated clearance is involved. Potential exceptions are compounds with significant biliary and/or extra-hepatic clearance. The method offers an alternative approach to more accurately predict human hepatic clearance when multiple complex mechanisms are involved.

\section{Introduction}

Pharmacology and toxicology effects are driven by free drug exposure at the site of action (e.g., blood, liver, brain, and muscle) (Smith et al., 2010). Therefore, the accurate prediction of human pharmacokinetics (PK) and tissue exposure is critically important in modern drug discovery. PK information not only enables medicinal chemistry design to achieve optimal dosing regimen but also helps the planning of clinical studies during early drug developmental phases. Over the past decade, significant progress has been made in predicting hepatic metabolic clearance mediated by such drug-metabolizing enzymes as cytochrome P450s and UDP-glucuronosyltransferases (UGT) (Kilford et al., 2009; Hallifax et al., 2010; Di et al., 2012b, 2013). These advances, in conjunction with high-throughput screening of metabolic stability and early metabolite identification, enable project teams to successfully reduce metabolic clearance so significantly that low-clearance assays are often needed to measure intrinsic clearance of many drug discovery

https://doi.org/10.1124/dmd.118.085639. compounds (Di and Obach, 2015). Although metabolism is the major elimination pathway for most drugs, the role of transporters has been increasingly recognized in drug clearance (Kalliokoski and Niemi, 2009). For example, organic anion-transporting polypeptide (OATP) 1B1 and 1B3 play essential roles in hepatic clearance of statins, sartans, and glinides. Compared with enzyme-mediated processes, predicting transporter-mediated clearance is highly uncertain. Human translation for transporter-mediated clearance is challenging since transporter activity is different between in vitro systems and in vivo, so empirical scaling factors are required to correct rates derived from in vitro assays. This phenomenon has been reported in multiple studies and was summarized in a previously published review (Li et al., 2014a). The use of empirical scaling factors substantially decreases our ability to predict human PK because the values can be assay- and compounddependent ( $\mathrm{Li}$ et al., 2014a). For novel compounds in drug discovery, it becomes difficult to determine which scaling factors should be used to predict human PK. This problem was partially resolved when global scaling factors were identified as being applicable to multiple OATP substrates (Li et al., 2014b). However, for compounds with hepatic

ABBREVIATIONS: AFE, average fold error; BSA, bovine serum albumin; $\mathrm{CL}_{\mathrm{H}}$, systemic plasma clearance mediated by hepatic elimination; $\mathrm{CL}_{\mathrm{H} \text {,int }}$,

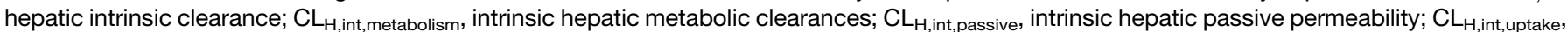
intrinsic hepatic uptake clearance; ECCS, extended clearance classification system; IVIVE, in vitro-to-in vivo extrapolation; Kp, hepatocyte-tobuffer partitioning ratio; LC-MS/MS, liquid chromatography-tandem mass spectrometry; NTCP, sodium-taurocholate cotransporting polypeptide;

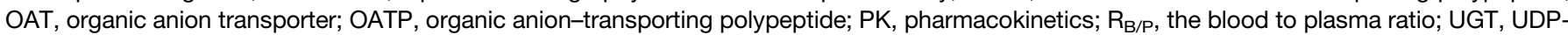
glucuronosyltransferases. 
uptake clearance that are not mediated by OATPs but by other transporters [e.g., sodium-taurocholate cotransporting polypeptide (NTCP) or organic anion transporters (OATs)], it is not clear if OATPs and other transporters share the same scaling factors. Another limitation is that the estimated scaling factors for active uptake of OATP substrates are usually quite high [e.g., 10-150 (Li et al., 2014a)], indicating that in vitro transporter activities are much lower than in vivo. Even weak signals from the in vitro systems can be translated to major uptake clearance in vivo. As such, in vitro systems often fail to identify OATP substrates that have weak signals owing to poor sensitivity, especially for highly lipophilic compounds with high passive permeability, despite the fact that transporters may actually play a significant role in their in vivo clearance. This makes it difficult to develop structure-transporter relationships and build confidence in in vivo human translation from in vitro transporter assays. Furthermore, with the current approaches, the major clearance pathway for a compound must be determined in order to know which method of PK prediction to use. For example, suspended human hepatocyte stability or human liver microsomal stability assays are typically used to predict human hepatic clearance if metabolism is the dominant clearance pathway, whereas plated human hepatocyte uptake assays may be used if transporter uptake is the rate-determining step for clearance. Determination of major clearance pathways is challenging, especially when in vitro-to-in vivo translation is disposition-, pathway-, and compound-dependent.

Facing these challenges, we have developed a novel method to predict human in vivo hepatic clearance for compounds that are potential substrates for drug-metabolizing enzymes and/or transporters. This new approach eliminates the use of empirical scaling factors for in vitro-toin vivo extrapolation (IVIVE) by using the extended clearance concept. Compared with the current available methods in the literature, this approach improves the precision and accuracy of prediction. More importantly, it uses a unified method to predict human hepatic clearance independent of disposition pathways of enzyme-mediated metabolism and/or transporter-mediated clearance. This significantly reduces the ambiguity and complexity, leading to increased confidence in human PK prediction regardless of the major clearance mechanism.

\section{Materials and Methods}

Materials. Test compounds were obtained from Pfizer Compound Management and Distribution (Groton, CT) or Sigma-Aldrich (St. Louis, MO). Cryopreserved human hepatocytes (Lot DCM, custom-pooled, 10 donors, male and female) were from BioreclamationIVT, LLC (Hicksville, NY). The individual donors were genotyped for the major drug-metabolizing enzymes and transporters, and the donors are mostly wild-type. Human plasma was from Sera Laboratories International Ltd (a division of BioreclamationIVT, West Sussex, UK) and human blood was obtained from Clinical Trials Laboratory Services Ltd (London, UK). Williams' medium E (WEM Gibco-BRL, cat. no. C1984, custom formula number 91-5233EC) contained $26 \mathrm{mM}$ sodium bicarbonate and $50 \mathrm{mM}$ HEPES. InVitroGRO HI media and MPER buffer were obtained from Thermo Fisher Scientific (Waltham, MA). The equilibrium dialysis device (96-well format) and cellulose membranes (MWCO 12-14K) were from HTDialysis, LLC (Gales Ferry, CT). Breathe Easy sealing membranes, bovine serum albumin (BSA; free of fatty acid, cat. no. A4612) and other reagents were purchased from Sigma-Aldrich unless specified.

Measurement of Metabolic Stability in Human Hepatocytes. Metabolic stability of compounds was determined using cryopreserved suspended human hepatocytes in the standard 4-hour incubation assay for high-to-moderateclearance compounds (Di et al., 2012a) or 20-hour hepatocyte relay assay for low-clearance compounds (Di et al., 2012b). The detailed relay protocols have been reported previously (Di et al., 2012a,b). Briefly, test compounds were added to suspended human hepatocytes at 0.5 or 2 million cells $/ \mathrm{ml}$ in WEM buffer and incubated at $37^{\circ} \mathrm{C}$ in a humidified $\mathrm{CO}_{2}$ incubator $(75 \%$ relative humidity, $5 \%$ $\mathrm{CO}_{2} / \mathrm{air}$ ) for 4 hours on an orbital shaker (150 rpm). For compounds that do not have significant turnover, 5 days of 4-hour incubations were used to give an accumulative relay-incubation time of 20 hours. At various time points, an aliquot of the sample was collected and quenched with cold acetonitrile containing internal standard(s) (CP-628374 or a cocktail of terfenadine, indomethacin, and metoprolol). Quenched solutions were centrifuged, and the supernatants were analyzed by liquid chromatography-tandem mass spectrometry (LC-MS/MS). The apparent metabolic intrinsic clearance $\left(C L_{H H E P, a p p}\right)$ was determined on the basis of the degradation half-life estimated from area ratio-time profile data.

Determination of Fraction Unbound. Human plasma protein binding and human liver microsomal assays were measured at Unilabs York Bioanalytical Solutions (York, UK). Binding in InVitroGRO HI media containing 4\% BSA was performed at Pfizer Groton laboratories. Equilibrium dialysis method was used for fraction unbound $\left(f_{u}\right)$ measurements as described previously (Riccardi et al., 2017). Briefly, the dialysis membranes and dialysis device were assembled following the manufacturer instructions (HTDialysis, LLC). Human plasma, BSA media, or human liver microsomes $(0.7-0.8 \mathrm{mg} / \mathrm{ml})$ containing 1 or $2 \mu \mathrm{M}$ test compounds with $1 \%$ dimethyl sulfoxide were dialyzed against phosphate buffered saline (PBS) for 6 hours in a humidified incubator (75\% relative humidity, 5\% $\mathrm{CO}_{2} / 95 \%$ air) at $37^{\circ} \mathrm{C}$ with shaking at $200 \mathrm{rpm}$ for 6 hours. Quadruplicates of binding were measured for each compound. Samples were matrix-matched and quenched with cold acetonitrile containing internal standard(s). The solutions were centrifuged and the supernatants were analyzed with LC-MS/MS. Presaturation method was also used for highly bound compounds (Riccardi et al., 2015). Calculation of fraction unbound has been discussed previously (Riccardi et al., 2015, 2016, 2017).

Determination of Blood-to-Plasma Ratio. Human blood-to-plasma ratio was measured by Unilabs York Bioanalytical Solutions. Test compounds were incubated with fresh human blood at $1 \mu \mathrm{M}$ concentration in quadruplicate in a humidified incubator ( $95 \%$ relative humidity, $5 \% \mathrm{CO}_{2} / 95 \%$ air) at $37^{\circ} \mathrm{C}$ with shaking at $450 \mathrm{rpm}$ for 1 and 3 hours. At the end of incubations, plasma samples were obtained by centrifuging blood samples at $3000 \mathrm{~g}$ for 7 minutes. Both plasma and blood samples were matrix-matched with each other and quenched with acetonitrile containing internal standard. The solutions were centrifuged, and the supernatants were analyzed by LC-MS/MS. Peak area ratios were used to calculate blood-to-plasma ratio.

In Vitro Buffer-Partitioning Ratio Measurement. The method for hepatocyteto-buffer-partitioning ratio $\left(K p_{H H E P}\right)$ measurement has been discussed previously (Riccardi et al., 2017). Briefly, test compounds $(1 \mu \mathrm{M})$ were added to suspended human hepatocytes ( 0.5 million cells $/ \mathrm{ml})$ in either WEM buffer or InVitroGRO HI media containing $4 \% \mathrm{BSA}$ and incubated on an orbital shaker $(150 \mathrm{~g})$ in a $37^{\circ} \mathrm{C}$ humidified incubator ( $75 \%$ relative humidity, $5 \% \mathrm{CO}_{2} / 95 \%$ air) for $1-4$ hours in duplicate. At the end of the incubation, the suspended cells were centrifuged ( $500 \mathrm{~g}, 3$ minutes) and supernatants were sampled. The remaining medium was removed and cells were washed twice with cold PBS and lysed with MPER buffer. Samples were quenched with cold acetonitrile containing internal standard and centrifuged. The supernatants were transferred for LC-MS/MS analysis using standard curves from both cells and media. $K p$ is the total cell concentration divided by the total buffer concentration.

Physiochemical Property Measurements. Physiochemical properties including $\log D_{7.4}, p K a$, and permeability $\left(P_{a p p}\right)$ measurements were conducted using methods reported previously (Shalaeva et al., 2008; Di et al., 2011; Li et al., 2014c).

LC-MS/MS Quantification. A generic LC-MS/MS method is presented here and similar methods were used on the basis of compound properties. Liquid chromatography mobile phases were: (A) $0.1 \%$ formic acid in water, (B) $0.1 \%$ formic acid in acetonitrile. Solvent gradient was run from $5 \%$ (B) to $95 \%$ (B) over 1.1 minutes at a flow rate of $0.5 \mathrm{ml} / \mathrm{min}$. Ultra-performance liquid chromatography column (BEH C18, $1.7 \mu \mathrm{m}, 50 \times 2.1 \mathrm{~mm}$; Waters, Milford, MA) was used and the injection volume was $10 \mu \mathrm{l}$. A CTC PAL autosampler (LEAP Technologies, Carrboro, NC), an Agilent 1290 binary pump (Santa Clara, CA), and an AB Sciex (Foster City, CA) API 6500 triple quadrupole mass spectrometer with a TurboIonSpray source in MRM mode were used for sample analysis. Analyst 1.6.1 software (Applied Biosystems, Foster City, CA) was used for data collection and analysis.

Mathematical Model. The extended clearance concept defines hepatic intrinsic clearance $\left(C L_{H, \text { int }}\right)$ as a function of metabolic $\left(C L_{H, \text { int,metabolism }}\right)$, biliary efflux $\left(C L_{H, \text { int, biliary }}\right)$, passive permeability $\left(C L_{H, \text { int,passive }}\right)$, and hepatic uptake $\left(C L_{H, \text { int,uptake }}\right)$ intrinsic clearances. 


$$
C L_{H, \text { int }}=\frac{\left(C L_{H, \text { int,metabolism }}+C L_{H, \text { int }, \text { biliary }}\right)\left(C L_{H, \text { int } t \text { uptake }}+C L_{H, \text { int,passive }}\right)}{\left(C L_{H, \text { int,metabolism }}+C L_{H, \text { int }, \text { biliary }}+C L_{H, \text { int, passive }}\right)}
$$

Our method (i.e., Method 1) assumes that (1) in vitro $C L_{H, \text { int,uptake }}$ values with BSA are equivalent to the in vivo $C L_{H, \text { int, uptake }}$ values, and (2) in vitro $C L_{H, \text { int,metabolism }}$ and $C L_{H, \text { int,passive }}$ values with (or without) BSA are equivalent to the in vivo values. Alternatively, we assume that 1) BSA is only required for the hepatic active uptake in vitro-in vivo ratio to be one (without BSA, the in vitro assay under-predicts in vivo active uptake); and 2) in vitro metabolism (and passive diffusion) values with and without BSA are the same, hence the in vitro-in vivo ratios are one regardless of the use of BSA in the assay. The traditional method (i.e., Method 2) assumes that in vitro $C L_{H, \text { int, metabolism, }}$

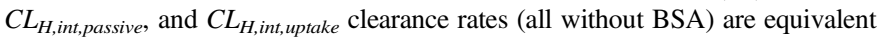
to the in vivo clearance rates. Since we do not have an in vitro tool to estimate $C L_{H, \text { int, biliary }}$, it is assumed to be zero for both methods.

All equations are derived assuming (pseudo-) steady state and well-stirred conditions. Assuming that metabolism is the only elimination pathway in the liver, the amount of compound in the liver plasma eliminated by $C L_{H, \text { int }}$ is equivalent to the amount of liver intracellular compound eliminated through $C L_{H, \text { int,metabolism. }}$.

$$
\begin{array}{r}
C L_{H, \text { int }} \cdot C_{\text {liver,plasma }} \cdot f_{u, p}=C L_{H, \text { int,metabolism }} \cdot C_{\text {liver,intracellular }} \cdot f_{u, \text { intracellular }} \\
\begin{aligned}
C L_{H, \text { int }} & =\frac{C L_{H, \text { int,metabolism }} \cdot C_{\text {liver,intracellular }} \cdot f_{u, \text { intracellular }}}{C_{\text {liver,plasma }} \cdot f_{u, p}} \\
& =C L_{H, \text { int,metabolism }} \cdot K p_{\text {uu,liver } / \text { liver,plasma }}
\end{aligned}
\end{array}
$$

$f_{u, p}$ and $f_{u, \text { intracellular }}$ are the unbound plasma fraction and unbound hepatocyte intracellular fraction. $K p_{\text {uu,liver/liver,plasma }}$ is the unbound liver tissue-to-liver plasma partitioning ratio. Please note that this parameter is not equivalent to the unbound liver tissue-to-systemic plasma partitioning ratio $\left(K p_{u u, l i v e r}\right)$. $C L_{H, \text { int,metabolism }}$ is predicted with the intrinsic hepatocyte metabolic clearance without BSA $\left(C L_{H H E P, \text { int }}\right)$ and a physiological scaling factor $(P S F)$. The value of $P S F$ is calculated as the product of human liver weight per body weight (i.e., $21 \mathrm{~g} / \mathrm{kg}$ ) and human hepatocytes per liver weight (i.e., 120 million hepatocytes $/ \mathrm{g}$ ).

$$
C L_{H, \text { int,metabolism }}=C L_{H H E P, \text { int }} \cdot P S F
$$

$C L_{H H E P, \text { int }}$ is estimated using apparent metabolic intrinsic clearance estimated from suspended human hepatocyte without BSA $\left(C L_{H H E P, a p p}\right)$ after accounting for the potential asymmetric distribution owing to residual transporter activity in the suspended hepatocyte assay.

$$
C L_{H H E P, \text { int }}=\frac{C L_{H H E P, a p p} \cdot\left(V_{\text {inc }}-V_{\text {cell }} \cdot\left(1-K p_{H H E P}\right)\right)}{K p_{H H E P} \cdot f_{\text {u,intracellular }} \cdot V_{\text {inc }}}
$$

$V_{\text {inc }}$ and $V_{\text {cell }}$ are the total incubation $(0.9987 \mathrm{ml})$ and intracellular $(0.0013 \mathrm{ml})$ volumes of the suspended hepatocyte assay. The hepatocyte-to-buffer partitioning ratio $\left(K p_{H H E P}\right)$ is determined as the ratio of intracellular hepatocyte to buffer concentrations.

$$
K p_{H H E P}=C_{H H E P, \text { intracellular }} / C_{\text {buffer }}
$$

With the above equations, $C L_{H, i n t}$ is calculated as follows.

$$
\begin{gathered}
C L_{H, \text { int }}=C L_{H, \text { int,metabolism }} \cdot K p_{\text {uu,liver/liver,plasma }} \\
=C L_{H H E P, \text { int }} \cdot P S F \cdot K p_{\text {uu,liver/liver,plasma }} \\
=\frac{C L_{H H E P, a p p} \cdot\left(V_{\text {inc }}-V_{\text {cell }} \cdot\left(1-K p_{H H E P}\right)\right)}{K p_{H H E P} \cdot f_{u, \text { intracellular }} \cdot V_{\text {inc }}} \cdot P S F \cdot K p_{\text {uu,liver/liver,plasma }}
\end{gathered}
$$

In this study, $K p_{\text {uu,liver/liver,plasma }}$ is estimated as the hepatocyte-to-buffer partitioning ratio with BSA $\left(K p_{H H E P, B S A}\right)$ as follows.

$$
\begin{aligned}
K p_{\text {uu,liver/liver,plasma }}= & \left(C_{H H E P, B S A, \text { intracellular }} \cdot f_{u, \text { intracellular }}\right) / \\
& \left(C_{\text {buffer }, B S A} \cdot f_{u, \text { buffer }, B S A}\right) \\
= & K p_{H H E P, B S A} \cdot f_{u, \text { intracellular }} / f_{u, \text { buffer }, B S A}
\end{aligned}
$$

The parameters $f_{u, \text { buffer }}$ and $f_{u, b u f f e r, B S A}$ present the buffer unbound fraction with and without $4 \%$ BSA. $C_{H H E P, B S A, \text { intracellular }}$ and $C_{\text {buffer,BSA }}$ are the hepatocyte intracellular and buffer concentrations in the presence of $4 \%$ BSA. The dialysis assay is used to determine $f_{u, b u f f e r, B S A}$, while $f_{u, b u f f e r}$ is assumed to be 1 . Finally, $C L_{H, i n t}$ is calculated with the equation below.

$$
\begin{aligned}
C L_{H, \text { int }} & =\frac{C L_{H H E P, a p p} \cdot\left(V_{\text {inc }}-V_{\text {cell }} \cdot\left(1-K p_{H H E P}\right)\right)}{K p_{H H E P} \cdot f_{u, \text { intracellular }} \cdot V_{\text {inc }}} \cdot P S F \cdot K p_{\text {uu,liver } / \text { liver }, \text { plasma }} \\
& =C L_{H H E P, \text { app }} \cdot \frac{K p_{H H E P, B S A} \cdot\left(V_{\text {inc }}-V_{\text {cell }} \cdot\left(1-K p_{H H E P}\right)\right)}{K p_{H H E P} \cdot f_{u, \text { buffer }, B S A} \cdot V_{\text {inc }}} \cdot P S F
\end{aligned}
$$

It is worth noting that $C L_{H, i n t}$ is the hepatic intrinsic clearance referring to compound elimination from the unbound liver plasma. The following equations are used to predict systemic plasma clearance mediated by hepatic elimination $\left(C L_{H}\right)$, i.e., clearance referring to the compound elimination from unbound systemic plasma. The equation essentially calculates the extraction from the hepatic plasma flow assuming a well-stirred condition, where $Q_{H}$ represents hepatic blood flow ( $20 \mathrm{ml} / \mathrm{min}$ per kilogram) and $R_{B / P}$ represents the blood-toplasma ratio.

$$
C L_{H}=Q_{H} \cdot \frac{C L_{H, \text { int }} \cdot f_{u, p}}{C L_{H, \text { int }} \cdot f_{u, p} / R_{B / P}+Q_{H}}
$$

The observed $C L_{H}$ values are from previously published clinical studies, after subtraction of the renal clearance $\left(C L_{R}\right)$ from the total plasma clearance $\left(C L_{P}\right)$.

For comparison, $C L_{H, \text { int }}($ Method 2) is also calculated by a traditional approach without using hepatocyte $K p$ data (Hallifax et al., 2010).

$$
C L_{H, \text { int }}=\frac{C L_{H H E P, a p p}}{f_{u, H H E P}} \cdot P S F
$$

Here $f_{u, H H E P}$ represents the unbound fraction in a suspended hepatocyte study. $f_{u, H H E P}$ is assumed to be equivalent with the unbound fraction in liver microsomes $\left(f_{u, H L M}\right)$ under similar assay conditions $\left(f_{u, H L M}\right.$ at $1 \mathrm{mg} / \mathrm{ml}$ is similar to $f_{u, H H E P}$ at 1 million cells/ml) (Austin et al., 2005).

Assessing Prediction Accuracy and Precision. Prediction precision and accuracy was assessed with average fold error (AFE) eq. 12, and bias eq. 13, where AFE approximates variance from unity, and bias is the degree away from unity.

$$
\begin{aligned}
\mathrm{AFE} & =10^{\frac{1}{N} \cdot \sum\left|\log _{10} \frac{\text { Predicted }}{\text { Observed }}\right|} \\
\text { bias } & =10^{\frac{1}{N}} \cdot \sum \log _{10} \frac{\text { Predicted }}{\text { Observed }}
\end{aligned}
$$

$N$ is the number of observations.

\section{Results}

A novel in vitro method has been developed, hereafter referred to as Method 1, using suspended human hepatocytes with and without $4 \%$ BSA to measure metabolic stability and partition coefficients. Thirtytwo structurally diverse compounds are included in the current study, covering a wide range of physicochemical properties and five of the six ECCS (extended clearance classification system; 1a, 1b, 2, 3b, and 4) classes (Varma et al., 2015). The physicochemical and in vitro data are summarized in Table 1 for compounds less likely to have biliary excretion (i.e., ECCS class $1 \mathrm{a}, 1 \mathrm{~b}$ and 2 ) and in Table 2, for compounds with the potential for significant biliary excretion (i.e., ECCS classes $3 b$, and 4). The comparison between the predicted and observed hepatic clearance values are shown in Tables 3 and 4 for those two groups of compounds. For compounds without significant biliary excretion ( $n=19$ ), good IVIVE is observed for hepatic clearance using this novel extended clearance method (Method 1), where the compounds are centered along the unity line (Fig. 1A). Greater than $80 \%$ of the compounds (16 out of 19) have predictions within 3-fold of observed values. The outliers are pitavastatin, telmisartan, and theophylline. Conversely, when the traditional method (Method 2, which only includes metabolic clearance) is used, most compounds appear on the 
TABLE 1

Physicochemical properties and in vitro inputs for compounds without the potential for biliary excretion as the major clearance pathway

\begin{tabular}{|c|c|c|c|c|c|c|c|c|c|c|c|c|}
\hline & $M W$ & $\log D_{7.4}$ & $p K a$ & $P_{a p p}$ & ECCS & $R_{B / P}$ & $f_{u, p}$ & $f_{u, \text { buffer }, B S A}$ & $C L_{H H E P, a p p}$ & $K p_{H H E P}$ & $K p_{H H E P, B S A}$ & $f_{u, H L M}$ \\
\hline & $\mathrm{g} / \mathrm{mol}$ & & & $10^{-6} \mathrm{~cm} / \mathrm{s}$ & & & & & $\begin{array}{c}\mu \mathrm{l} / \mathrm{min} \text { per } \\
10^{6} \text { cells }\end{array}$ & & & \\
\hline Diclofenac & 296.2 & 1.2 & $4.4(\mathrm{~A})^{a}$ & 23 & $1 \mathrm{a}$ & 0.66 & 0.0038 & 0.0026 & 67 & 18 & 0.95 & 0.85 \\
\hline Ibuprofen & 206.3 & $0.9^{a}$ & $4.4(\mathrm{~A})^{a}$ & 31 & $1 \mathrm{a}$ & 0.55 & 0.012 & 0.018 & 24 & 8.5 & 0.21 & 0.95 \\
\hline Meloxicam & 351.4 & 0.5 & $4.0(\mathrm{~A})$ & 35 & $1 \mathrm{a}$ & 0.57 & 0.0082 & 0.020 & 2.1 & 22 & 0.92 & 0.92 \\
\hline Nateglinide & 317.4 & 1.1 & $3.8(\mathrm{~A})^{a}$ & 11 & $1 \mathrm{a}$ & $0.6^{b}$ & 0.011 & 0.0043 & 11 & 8.4 & 0.20 & $0.89^{a}$ \\
\hline Tolbutamide & 270.4 & 0.4 & $5.1(\mathrm{~A})^{a}$ & 26 & $1 \mathrm{a}$ & 0.56 & 0.030 & 0.058 & 1.8 & 0.69 & 0.14 & 0.91 \\
\hline Atorvastatin & 558.6 & 1.3 & $4.4(\mathrm{~A})^{a}$ & 1.9 & $1 b^{c}$ & 0.57 & 0.048 & 0.043 & 9.4 & 88 & 31 & 0.46 \\
\hline Bosentan & 551.6 & 1.1 & $4.7(\mathrm{~A})$ & 7.5 & $1 b$ & 0.67 & 0.028 & 0.034 & 5.6 & 44 & 8.2 & 0.63 \\
\hline Cerivastatin & 459.6 & 1.8 & $\begin{array}{l}4.6(\mathrm{~A}) \\
5.5(\mathrm{~B})\end{array}$ & 14 & $1 b$ & 0.56 & 0.018 & 0.019 & 13 & 121 & 12 & 0.47 \\
\hline Fluvastatin & 411.5 & 1.4 & $4.4(\mathrm{~A})$ & 11 & $1 b$ & 0.69 & 0.0092 & 0.025 & 33 & 32 & 6.2 & $0.70^{a}$ \\
\hline Glipizide & 445.5 & 0.4 & 4.9 (A) & 8.8 & $1 b$ & 0.60 & 0.040 & 0.063 & 2.0 & 3.2 & 0.55 & 0.95 \\
\hline Glyburide & 494.0 & 2.1 & $5.0(\mathrm{~A})$ & 14 & $1 b$ & 0.57 & 0.0024 & 0.0070 & 23 & 45 & 1.3 & 0.65 \\
\hline GSK269984A & 406.2 & 2.1 & $\begin{array}{l}2.3(\mathrm{~A})^{a} \\
5.9(\mathrm{~B})^{a}\end{array}$ & 14 & $1 b$ & 0.65 & 0.0024 & 0.00081 & 37 & 150 & 2.4 & 0.24 \\
\hline Irbesartan & 428.5 & 1.4 & $\begin{array}{l}4.3(\mathrm{~A})^{a} \\
7.0(\mathrm{~B})^{a}\end{array}$ & 9.3 & $1 b$ & 0.60 & 0.016 & 0.046 & 14 & 50 & 12 & 0.76 \\
\hline Montelukast & 586.2 & 5.1 & $\begin{array}{l}4.2(\mathrm{~A})^{a} \\
5.3(\mathrm{~B})^{a}\end{array}$ & $<0.1$ & $1 b^{c}$ & 0.67 & 0.000092 & 0.00019 & 9.6 & 1.9 & 0.17 & 0.00067 \\
\hline Pitavastatin & 421.5 & 1.2 & $\begin{array}{l}4.2(\mathrm{~A})^{a} \\
5.0(\mathrm{~B})^{a}\end{array}$ & 5.7 & $1 b$ & 0.55 & 0.0080 & 0.055 & 11 & 22 & 3.0 & 0.67 \\
\hline Repaglinide & 452.6 & 2.2 & $\begin{array}{l}4.3(\mathrm{~A}) \\
5.9(\mathrm{~B})\end{array}$ & 20 & $1 b$ & 0.86 & 0.012 & 0.0086 & 33 & 64 & 1.5 & 0.49 \\
\hline Telmisartan & 514.6 & 2.4 & $\begin{array}{l}4.1(\mathrm{~A}) \\
6.1(\mathrm{~B})\end{array}$ & 18 & $1 b$ & 0.61 & 0.0060 & 0.014 & 13 & 440 & 45 & 0.57 \\
\hline Theophylline & 180.2 & 0.1 & $8.6(\mathrm{~B})$ & 27 & 2 & 0.71 & 0.70 & 0.76 & 1.2 & 0.13 & 0.27 & 1.0 \\
\hline Timolol & 316.4 & $0.6^{a}$ & $8.6(\mathrm{~B})^{a}$ & 20 & 2 & 0.82 & 0.73 & 0.81 & 2.6 & 6.1 & 7.1 & 0.83 \\
\hline
\end{tabular}

A and B, acidic and basic $p K a$ values; $C L_{H H E P, a p p}$, apparent hepatocyte metabolic clearance; ECCS, extended clearance classification system; $f_{u, H L M}$, unbound fraction in liver microsomes; $f_{u, p}$, the unbound fraction in plasma; $K p_{H H E P, B S A}$, hepatocyte to buffer partitioning ratio with BSA; $P_{a p p}$, permeability; $R_{B / P}$, the blood-toplasma ratio.

${ }^{a}$ In silico.

${ }^{b}$ Assumed.

${ }^{c}$ On the basis of in vivo PK properties rather than RRCK $P_{a p p}$

right-hand bottom of the graph (Fig. 1B), indicating a systemic underprediction of hepatic clearance. Only $26 \%$ (5 out of 19 compounds) of the predicted hepatic clearance values are within 3 -fold of the observed values, suggesting that transporter-mediated clearance plays a significant role in addition to metabolic clearance. Similar trends are observed for the prediction of hepatic intrinsic clearance using Methods 1 and 2 (Fig. 1, C and D). Applying Methods 1 and 2 to the compounds in Table 1, the AFE values for hepatic clearance $\left(C L_{H}\right)$ are 1.9 and 4.1 , and the bias values are 0.84 and 0.30 , respectively (Table 3). The smaller AFE value and the bias value closer to one both indicate that Method 1 is more accurate and precise, consistent with what has been observed in Fig. 1. Likewise, with Methods 1 and 2, the AFE values for intrinsic hepatic clearance $\left(C L_{H, \text { int }}\right)$ are 2.5 and 5.8, and the bias values are 0.71 and 0.21 , respectively. This indicates that

TABLE 2

Physicochemical properties and in vitro inputs for compounds with the potential for biliary excretion as the major clearance pathway

\begin{tabular}{|c|c|c|c|c|c|c|c|c|c|c|c|c|}
\hline & $M W$ & $\log D_{7.4}$ & $p K a$ & $P_{a p p}$ & ECCS & $R_{B / P}$ & $f_{u, p}$ & $f_{u, \text { buffer }, B S A}$ & $C L_{H H E P, a p p}$ & $K p_{H H E P}$ & $K p_{H H E P, B S A}$ & $f_{u, H L M}$ \\
\hline & $\mathrm{g} / \mathrm{mol}$ & & & $10^{-6} \mathrm{~cm} / \mathrm{s}$ & & & & & $\begin{array}{c}\mu l / m i n ~ p e r \\
10^{6} \text { cells }\end{array}$ & & & \\
\hline Lesinurad & 404.3 & 0.5 & $3.1(\mathrm{~A})$ & 1.0 & $3 b$ & 0.60 & 0.010 & 0.0040 & 2.9 & 53 & 0.82 & $0.68^{a}$ \\
\hline Losartan & 422.9 & $1.7^{a}$ & $4.5(\mathrm{~A})^{a}$ & 1.3 & $3 b$ & 0.62 & 0.029 & 0.017 & 9.3 & 56 & 7.8 & 0.79 \\
\hline PF-05089771 & 500.45 & 2.3 & $6.0(\mathrm{~A})$ & 3.8 & $3 b$ & 0.60 & 0.0015 & 0.0059 & 11 & 34 & 2.8 & 0.41 \\
\hline PF-05150122 & 541.0 & 1.1 & $\begin{array}{l}6.5(\mathrm{~A}) \\
7.4(\mathrm{~B})\end{array}$ & 3.2 & $3 b$ & 0.64 & 0.065 & 0.18 & 5.8 & 27 & 6.3 & 0.85 \\
\hline PF-05186462 & 531.9 & 0.8 & $4.1(\mathrm{~A})$ & 0.81 & $3 b$ & 0.66 & 0.0016 & 0.015 & 2.4 & 24 & 4.1 & 0.67 \\
\hline PF-05241328 & 436.9 & 2.0 & $3.6(\mathrm{~A})$ & 3.9 & $3 b$ & 0.56 & 0.0020 & 0.0084 & 10 & 300 & 2.8 & 0.38 \\
\hline Pravastatin & 424.5 & -0.4 & $4.3(\mathrm{~A})$ & 0.31 & $3 b$ & 0.55 & 0.63 & 0.49 & 0.29 & 1.7 & 9.4 & 0.80 \\
\hline Rosuvastatin & 481.5 & 0.1 & $4.3(\mathrm{~A})$ & 0.75 & $3 b$ & 0.57 & 0.16 & 0.19 & 0.32 & 14 & 24 & 0.77 \\
\hline Valsartan & 435.5 & -0.8 & $\begin{array}{l}3.4(\mathrm{~A}) \\
4.7(\mathrm{~A})\end{array}$ & 0.32 & $3 b$ & 0.70 & 0.0041 & 0.0060 & 0.58 & 14 & 0.88 & 0.79 \\
\hline Disopyramide & 339.5 & $0.6^{a}$ & $9.4(\mathrm{~B})^{a}$ & 1.3 & 4 & 0.70 & 0.37 & 0.88 & 1.2 & 3.0 & 4.6 & 0.94 \\
\hline Maraviroc & 513.7 & 12.0 & 9.4 (B) & 1.8 & 4 & 0.68 & 0.51 & 0.33 & 1.9 & 4.6 & 3.3 & 0.64 \\
\hline Ranitidine & 314.4 & -0.7 & $8.5(\mathrm{~B})$ & 0.57 & 4 & 1.0 & 0.84 & 1.0 & 1.7 & 2.1 & 1.3 & $0.95^{a}$ \\
\hline Zolmitriptan & 287.4 & $0.4^{a}$ & $8.9(\mathrm{~B})^{a}$ & $<0.1$ & 4 & $1^{b}$ & 0.75 & 0.84 & 0.26 & 3.0 & 4.1 & 0.84 \\
\hline
\end{tabular}

A and B, acidic and basic $p K a$ values; $f_{u, \text { buffer }}$, unbound fraction in buffer without BSA; $f_{u, b u f f e r, B S A}$, unbound fraction in buffer with BSA; ECCS, extended clearance classification system; $R_{B / P}$, the blood-to-plasma ratio.

${ }^{a}$ In silico.

${ }^{b}$ Assumed. 
TABLE 3

Predicted human and observed human hepatic clearance for compounds without the potential for biliary excretion as the major clearance pathway

\begin{tabular}{|c|c|c|c|c|c|c|c|}
\hline Compound & Observed $C L_{H}$ & $\begin{array}{l}\text { Predicted } C L_{H} \\
\quad \text { Method } 1\end{array}$ & $\begin{array}{l}\text { Predicted } C L_{H} \\
\quad \text { Method } 2\end{array}$ & $\begin{array}{c}\text { Observed } \\
C L_{H, \text { int }}\end{array}$ & $\begin{array}{l}\text { Predicted } C L_{H, i n t} \\
\quad \text { Method } 1\end{array}$ & $\begin{array}{c}\text { Predicted } \\
C L_{H, i n t} \text { Method } 2\end{array}$ & Reference for Observed Values \\
\hline & $\begin{array}{l}\mathrm{ml} / \text { min per } \\
\text { kilogram }\end{array}$ & $\mathrm{ml} / \mathrm{min}$ per kilogram & $\mathrm{ml} / \mathrm{min}$ per kilogram & $\begin{array}{l}\text { ml/min per } \\
\text { kilogram }\end{array}$ & $\mathrm{ml} / \mathrm{min}$ per kilogram & $\begin{array}{l}\text { ml/min per } \\
\text { kilogram }\end{array}$ & \\
\hline Diclofenac & 4.1 & 6.5 & 0.67 & 1500 & 3400 & 190 & Willis et al., 1979; NDA-207238, 2017 \\
\hline Ibuprofen & 0.89 & 0.93 & 0.71 & 79 & 83 & 62 & $\begin{array}{l}\text { Bushra and Aslam, 2010; Pavliv et al., } \\
2011\end{array}$ \\
\hline Meloxicam & 0.16 & 0.093 & 0.045 & 20 & 11 & 5.5 & Schmid et al., 1995 \\
\hline Nateglinide & 1.3 & 1.5 & 0.35 & 120 & 150 & 30 & Weaver et al., 2001 \\
\hline Tolbutamide & 0.18 & 0.46 & 0.15 & 6.1 & 16 & 5.0 & $\begin{array}{l}\text { Scott and Poffenbarger, 1979; } \\
\text { Flesch et al., } 1997\end{array}$ \\
\hline Atorvastatin & 8.9 & 5.4 & 1.7 & 890 & 220 & 41 & Lennernas, 2003 \\
\hline Bosentan & 2.2 & 2.0 & 0.52 & 92 & 84 & 19 & Weber et al., 1996 \\
\hline Cerivastatin & 2.7 & 2.6 & 0.89 & 200 & 190 & 55 & Muck et al., 1997; Muck, 2000 \\
\hline Fluvastatin & 7.3 & 4.2 & 0.91 & 1700 & 660 & 110 & Tse et al., 1992; Lindahl et al., 1996 \\
\hline Glipizide & 0.53 & 0.55 & 0.21 & 14 & 14 & 5.3 & Pentikainen et al., 1983 \\
\hline Glyburide & 1.2 & 0.60 & 0.18 & 580 & 260 & 78 & $\begin{array}{l}\text { Neugebauer et al., 1985; } \\
\quad \text { Varma et al., } 2009\end{array}$ \\
\hline GSK269984A & 2.0 & 3.8 & 0.63 & 980 & 2200 & 280 & Ostenfeld et al., 2012 \\
\hline Irbesartan & 2.1 & 2.4 & 0.64 & 160 & 200 & 43 & Vachharajani et al., 1998 \\
\hline Montelukast & 0.57 & 0.99 & 1.8 & 6400 & 12,000 & 23,000 & Cheng et al., 1996; Balani et al., 1997 \\
\hline Pitavastatin & 5.6 & 0.53 & 0.28 & 1400 & 70 & 36 & NDA-022363, 2009 \\
\hline Repaglinide & 7.3 & 2.6 & 1.5 & 1000 & 250 & 140 & Hatorp et al., 1998; NDA-020741, 2017 \\
\hline Telmisartan & 10 & 1.8 & 0.27 & 10,000 & 360 & 47 & Stangier et al., 2000a,b \\
\hline Theophylline & 0.87 & 4.0 & 1.8 & 1.3 & 8.0 & 2.9 & $\begin{array}{l}\text { Conrad and Nyman, 1980; Caldwell } \\
\text { et al., 1986; Vestal et al., 1986; } \\
\text { Lombardi et al., 1987; NDA-019211, } \\
2009\end{array}$ \\
\hline Timolol & 6.4 & 4.8 & 4.0 & 14 & 9.3 & 7.3 & $\begin{array}{l}\text { Wilson et al., 1982; McGourty et al., } \\
1985\end{array}$ \\
\hline $\mathrm{N}$ & & 19 & 19 & & 19 & 19 & \\
\hline AFE & & 1.9 & 4.1 & & 2.5 & 5.8 & \\
\hline bias & & 0.84 & 0.30 & & 0.71 & 0.21 & \\
\hline
\end{tabular}

ECCS, extended clearance classification system.

Method 1 also performs much better than Method 2 in predicting intrinsic clearance.

For compounds with potentially significant biliary excretion (i.e., ECCS $3 \mathrm{a}, 3 \mathrm{~b}$, and 4 compounds in Table 2, $\mathrm{n}=13$ ), $38 \%$ (5 out of 13 compounds) of the predicted hepatic clearance values are within 3-fold (Fig. 2A) with Method 1. When Method 2 is applied, 23\% (3 out of 13 compounds) of the predicted values are within 3-fold (Fig. 2B). Intrinsic clearance values are also under-predicted (Fig. 2, C and D).
Consistent with data shown in the plots, large AFE values and bias values deviating from one are observed for this group of compounds with biliary clearance (Table 4 ).

\section{Discussion}

Significant advances have been made over the years in predicting human metabolic clearance. However, prediction of human hepatic

TABLE 4

Predicted human and observed human hepatic clearance for compounds with the potential for biliary excretion as the major clearance pathway

\begin{tabular}{|c|c|c|c|c|c|c|c|}
\hline Compound & Observed $C L_{H}$ & $\begin{array}{l}\text { Predicted } C L_{H} \\
\quad \text { Method } 1\end{array}$ & $\begin{array}{l}\text { Predicted } C L_{H} \\
\quad \text { Method } 2\end{array}$ & $\begin{array}{c}\text { Observed } \\
C L_{H, \text { int }}\end{array}$ & $\begin{array}{l}\text { Predicted } C L_{H, \text { int }} \\
\quad \text { Method } 1\end{array}$ & $\begin{array}{l}\text { Predicted } C L_{H, \text { int }} \\
\quad \text { Method } 2\end{array}$ & Reference for Observed Values \\
\hline & $\begin{array}{l}\mathrm{ml} / \mathrm{min} \mathrm{per} \\
\text { kilogram }\end{array}$ & $\begin{array}{l}\mathrm{ml} / \mathrm{min} \mathrm{per} \\
\text { kilogram }\end{array}$ & $\begin{array}{l}\mathrm{ml} / \text { min per } \\
\text { kilogram }\end{array}$ & $\begin{array}{l}\text { ml/min per } \\
\text { kilogram }\end{array}$ & $\begin{array}{l}\mathrm{ml} / \mathrm{min} \text { per } \\
\text { kilogram }\end{array}$ & $\begin{array}{l}\mathrm{ml} / \text { min per } \\
\text { kilogram }\end{array}$ & \\
\hline Lesinurad & 0.93 & 0.29 & 0.092 & 100 & 30 & 9.3 & Shen et al., 2015 \\
\hline Losartan & 7.5 & 4.1 & 0.75 & 630 & 210 & 27 & Lo et al., 1995 \\
\hline PF-05089771 & 0.17 & 0.59 & 0.079 & 120 & 410 & 53 & Jones et al., 2016 \\
\hline PF-05150122 & 3.2 & 1.2 & 0.98 & 64 & 20 & 16 & Jones et al., 2016 \\
\hline PF-05186462 & 1.3 & 0.12 & 0.013 & 890 & 74 & 8.0 & Jones et al., 2016 \\
\hline PF-05241328 & 5.7 & 0.077 & 0.10 & 5900 & 39 & 51 & Jones et al., 2016 \\
\hline Pravastatin & 7.3 & 3.5 & 0.50 & 34 & 7.9 & 0.83 & Singhvi et al., 1990 \\
\hline Rosuvastatin & 6.8 & 1.1 & 0.15 & 110 & 7.5 & 0.95 & Martin et al., 2003 \\
\hline Valsartan & 0.35 & 0.066 & 0.0071 & 85 & 16 & 1.7 & Flesch et al., 1997 \\
\hline Disopyramide & 0.30 & 1.6 & 1.0 & 0.84 & 5.0 & 3.0 & Lima et al., 1984 \\
\hline Maraviroc & 7.2 & 3.9 & 2.7 & 30 & 11 & 6.6 & Abel et al., 2008 \\
\hline Ranitidine & 2.6 & 2.1 & 3.2 & 3.6 & 2.8 & 4.4 & $\begin{array}{l}\text { Chau et al., 1982; van Hecken } \\
\text { et al., } 1982\end{array}$ \\
\hline Zolmitriptan & 8.7 & 0.78 & 0.54 & 21 & 1.1 & 0.73 & $\begin{array}{l}\text { Dixon et al., 1997; Seaber et al., } \\
1998\end{array}$ \\
\hline $\mathrm{N}$ & & 13 & 13 & & 13 & 13 & \\
\hline AFE & & 4.6 & 11 & & 6.4 & 16 & \\
\hline bias & & 0.34 & 0.12 & & 0.25 & 0.080 & \\
\hline
\end{tabular}



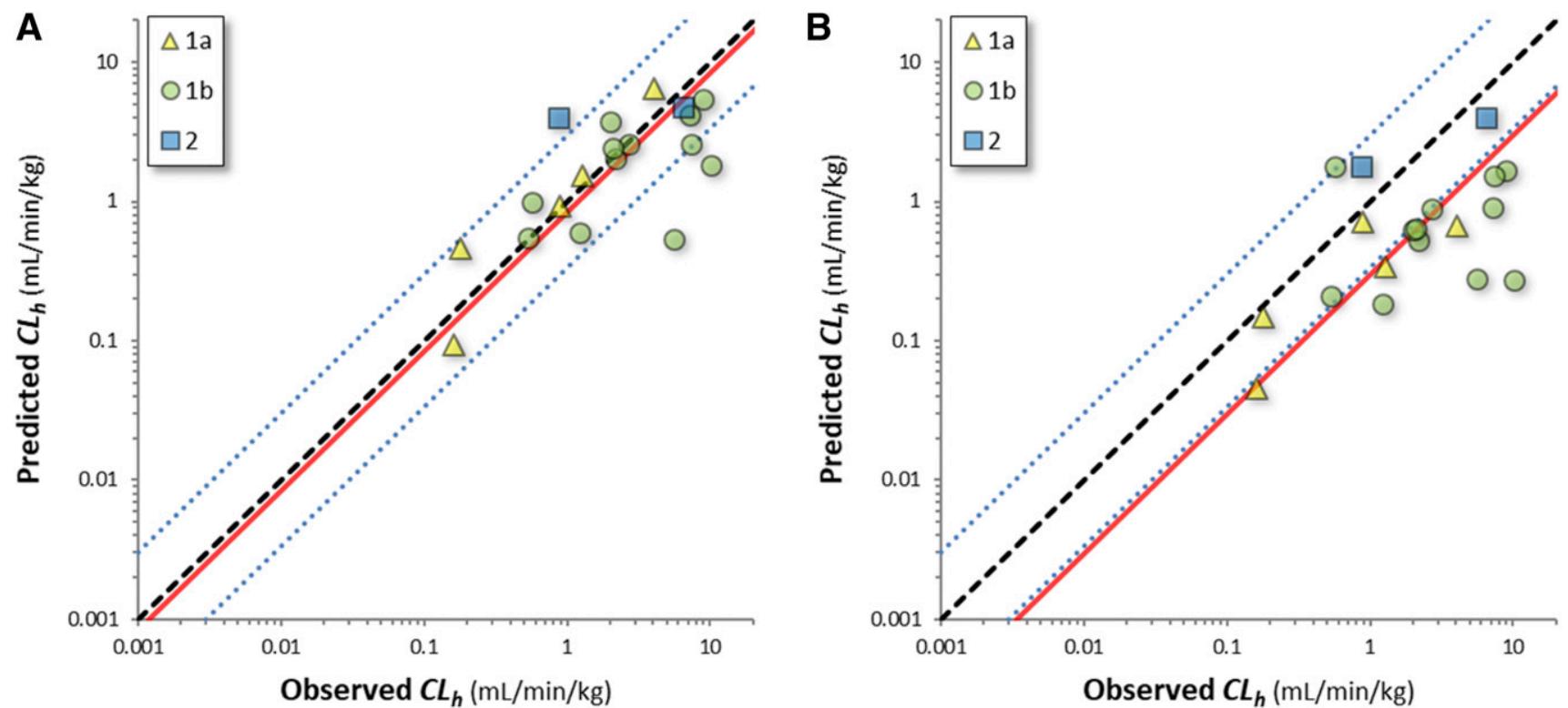

C
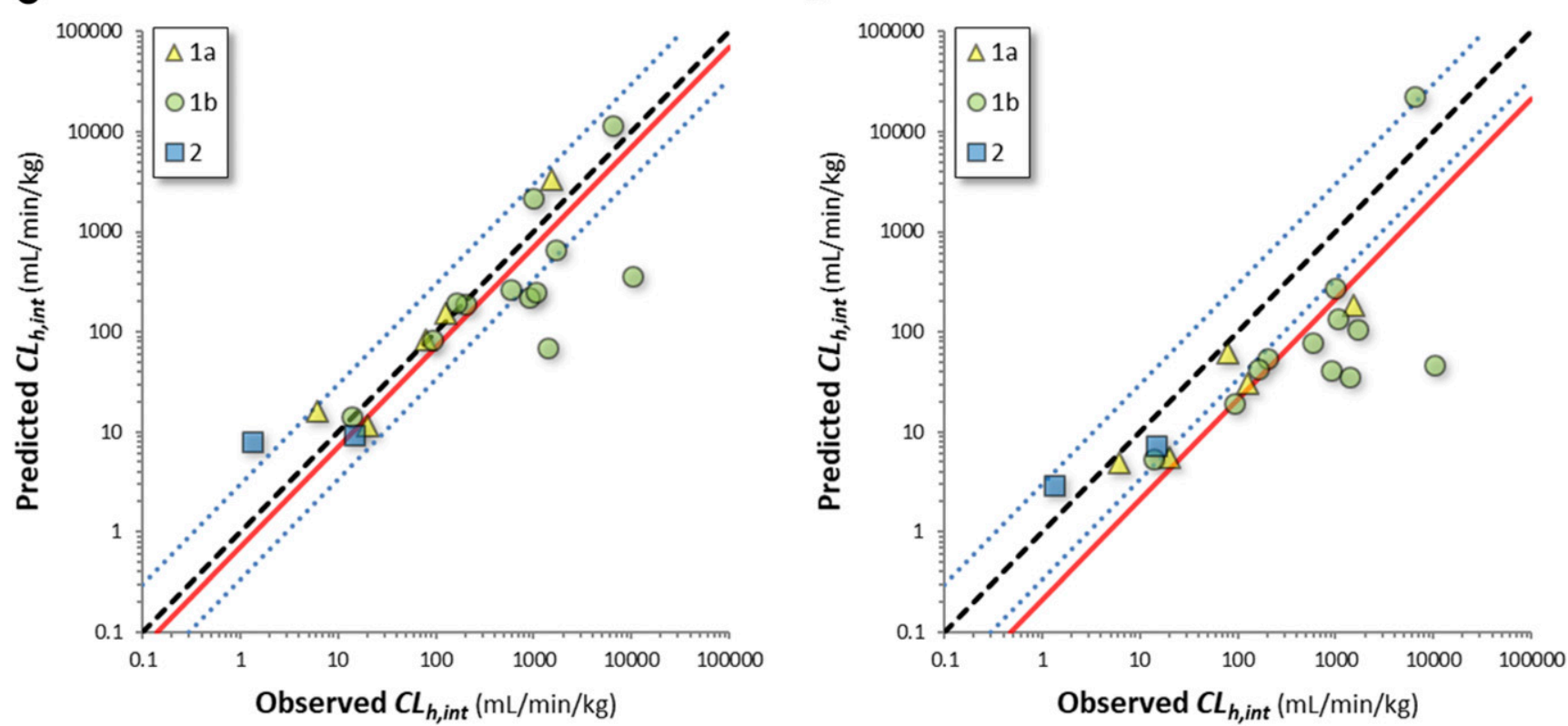

Fig. 1. Observed and predicted clearance for compounds without the potential for biliary excretion as a major clearance pathway. (A) Predicted systemic plasma clearance mediated by hepatic elimination $\left(C L_{H}\right)$ with the novel extended clearance method. (B) Predicted $C L_{H}$ with the traditional metabolic clearance method. (C) Predicted hepatic intrinsic clearance $\left(C L_{H, \text { int }}\right)$ with the novel extended clearance method. (D) Predicted $C L_{H, \text { int }}$ with the traditional metabolic clearance method. The black dashed, blue dotted, and red solid lines represent unity, 3-fold from unity, and method bias. Yellow triangles, green circles, and blue squares represent ECCS classes $1 \mathrm{a}, 1 \mathrm{~b}$, and 2 compounds.

clearance for complex mechanisms of enzyme-transporter interplay is still a major challenge in drug discovery and development. Although several new approaches have been developed, practical applications of the methods are limited in providing guidance for medicinal chemistry design and accurate predictions of human PK. The restrictions of these approaches, as highlighted in the introduction, result from the limitation of compound- and transporter-dependent scaling factors, inability to detect transporter activity for highly lipophilic permeable compounds, and the need to know the rate-determining step prior to clearance prediction. We have developed a novel experimental approach to predict human clearance for enzyme- and transporter-mediated mechanisms. This method was developed on the basis of liver-to-plasma $\left(K p_{u u}\right)$ work previously published (Riccardi et al., 2016, 2017). With these hypotheses as a basis: 1) The metabolic, passive, and uptake intrinsic clearance rates in the in vitro hepatocyte assay, in the presence of $4 \% \mathrm{BSA}$, are equivalent to in vivo rates, and 2) the metabolic intrinsic clearance rates in the in vitro hepatocyte assay, in the absence of $4 \% \mathrm{BSA}$, are equivalent to in vivo rates. Thus, we decided to expand this method to predict human clearance mediated by both drug metabolizing enzymes and transporters. A large set of structurally diverse compounds with different clearance mechanisms and transporter involvement (OATPs, NTCP, OATs) for which we have human in vitro clearance data were used for the method validation. This is the first study with a large set of compounds demonstrating strong human IVIVE for clearance involving transporters using a bottom up approach without any empirical scaling factors. This novel method incorporating the extended clearance concept with transporter effects provides a much better prediction of human clearance than using the traditional metabolic clearance alone. 
A

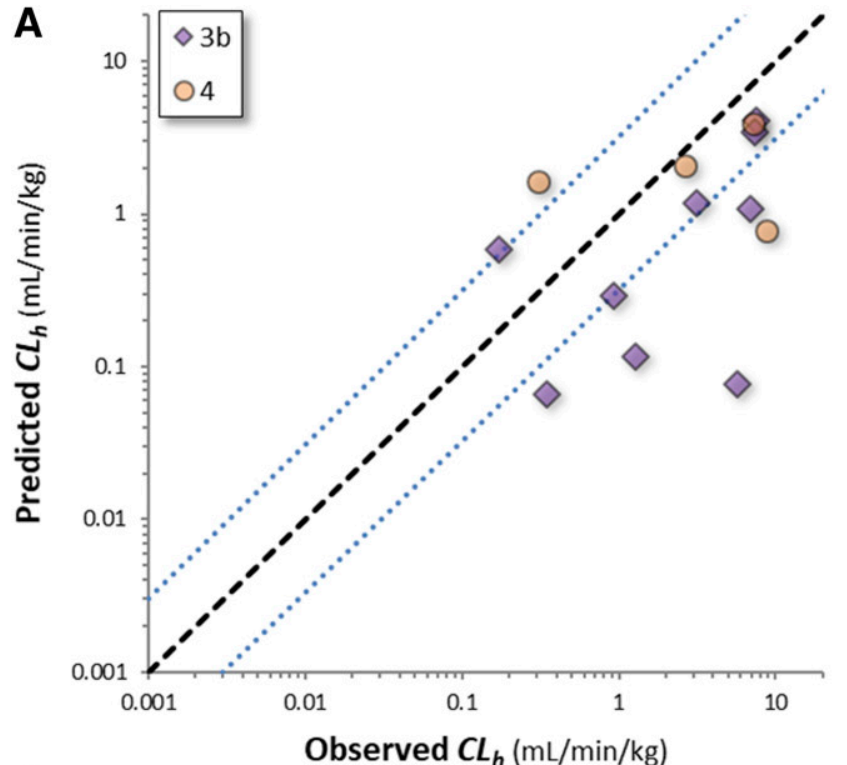

C

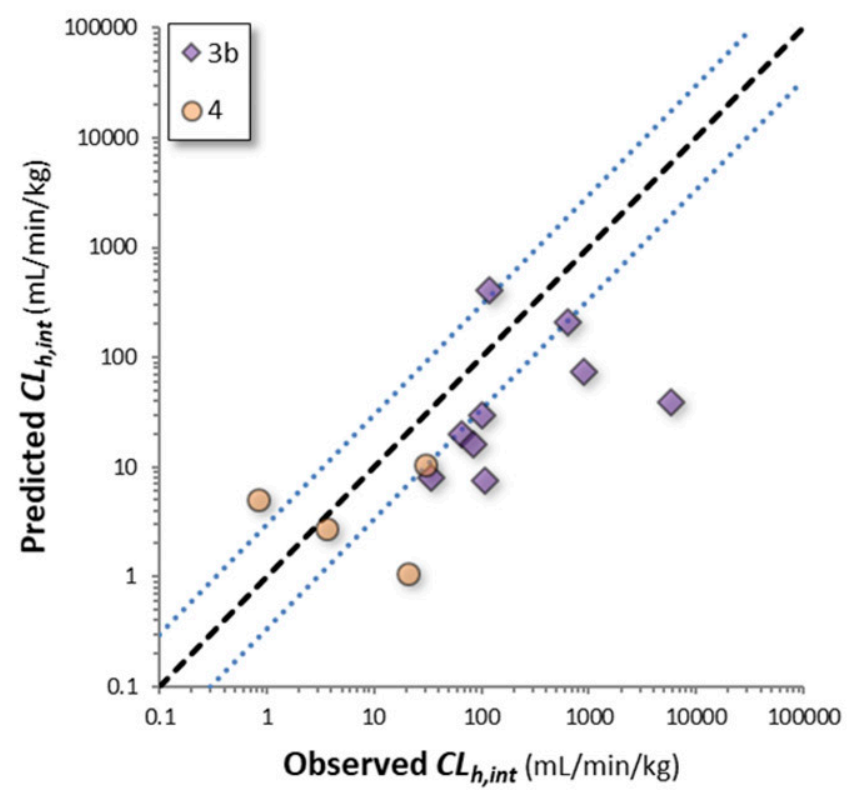

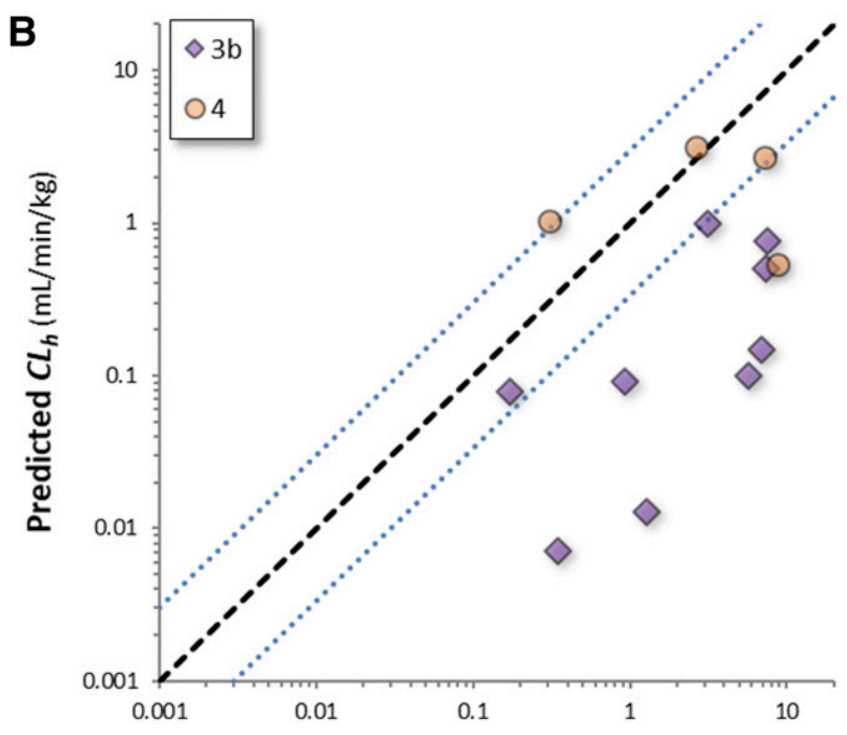

Observed $C_{h}(\mathrm{~mL} / \mathrm{min} / \mathrm{kg})$

D

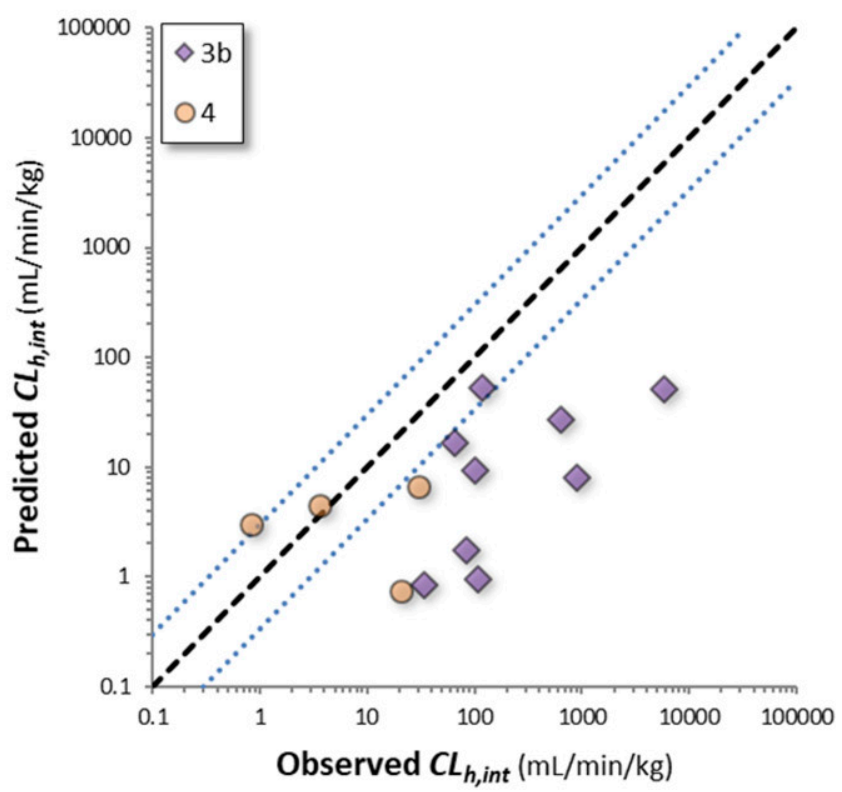

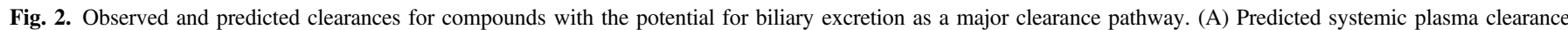

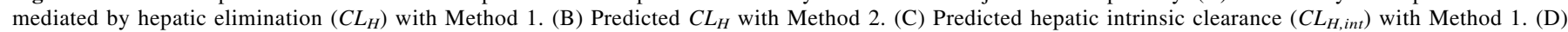

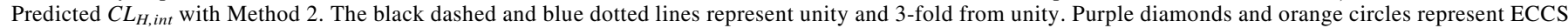
classes $3 \mathrm{~b}$ and 4 compounds.

The data obtained in this study are different from those using plated hepatocytes without BSA, where large scaling factors are required for uptake transporters to predict human PK (Jones et al., 2012; Li et al., $2014 b$ ). This indicates that the suspended hepatocytes in this novel in vitro system (InVitroGRO HI media supplemented with $4 \%$ BSA) are able to function in a manner similar to in vivo under physiologic conditions, leading to a possible translation from in vitro to in vivo without any scaling factors. The $4 \%$ BSA was used to mimic the physiologic amount of albumin and can be applied to various species. A similar phenomenon has been reported recently using plated human hepatocytes in human plasma, but the approach was only verified with pravastatin (Mao et al., 2018). In vitro hepatocyte systems supplemented with proteins appear to more closely mimic in vivo disposition, although the underlining mechanisms are not entirely clear. One explanation uses the "facilitated-dissociation" model as a basis, in which interaction of the albumin-drug complex with the cell surface enhances dissociation of the complex to provide more unbound drug molecules to be transported (Tsao et al., 1988; Miyauchi et al., 2018). This is an area to further investigate in the future.

Accurate measurement and prediction of human biliary clearance and enterohepatic recirculation continues to be particularly challenging. Since there is currently no reliable in vitro method to predict biliary excretion, we have assigned the biliary excretion to be zero for all compounds in this study. As expected, this assumption leads to underprediction of clearance for some compounds with significant biliary clearance (Fig. 2; Table 4). The magnitude of under-prediction is dependent upon the extent of biliary excretion that contributes to the total hepatic intrinsic clearance. These compounds are still included in the current analysis to test the extent of misprediction if the biliary clearance is arbitrarily fixed at zero owing to the lack of a method to 
accurately predict biliary excretion. The sandwich culture hepatocyte assay has been previously developed as a method to estimate biliary excretion. However, mechanistically translating the in vitro biliary clearance estimate in sandwich culture assay to in vivo biliary clearance is still challenging since compound-dependent scaling factors may be required, and high uncertainty is also associated with the estimated scaling factors (Li et al., 2014b). Furthermore, estimating in vivo biliary clearance from clinical pharmacokinetic data is usually confounded by the enterohepatic recirculation. As such, it is difficult to use in vivo biliary clearance to validate a prediction made by in vitro tools (such as sandwich-cultured human hepatocytes). This lack of good in vivo validation data can be a key missing piece in developing in vitro assays and using them in drug discovery. Hence, it will be helpful in the future if new modeling tools can be developed to estimate clinical biliary excretion and enterohepatic recirculation from existing systemic pharmacokinetic data, or if new experimental technology can be developed to directly measure these two processes. Clearance of two compounds (pitavastatan and telmisartan) mainly cleared by UGTs are underpredicted ( $>3$-fold) by the current approach. This could be attributable, in part, to extrahepatic metabolism contributed by some of the UGTs. Future understanding of extrahepatic metabolism will be required to increase our confidence in the clearance prediction of these groups of compounds.

\section{Authorship Contributions}

Participated in research design: Riccardi, Tess, Di, Li.

Conducted experiments: Riccardi, Lin, Patel, Ryu, Atkinson.

Contributed new reagents or analytic tools: Riccardi, Ryu, Tess.

Performed data analysis: Tess, Riccardi, Ryu, Atkinson, Lin, Patel, Di, Li.

Wrote or contributed to the writing of the manuscript: Riccardi, Ryu, Atkinson, Tess, Di, Li.

\section{References}

Abel S, Russell D, Whitlock LA, Ridgway CE, Nedderman ANR, and Walker DK (2008) Assessment of the absorption, metabolism and absolute bioavailability of maraviroc in healthy male subjects. Br J Clin Pharmacol 65 (Suppl 1):60-67.

Austin RP, Barton P, Mohmed S, and Riley RJ (2005) The binding of drugs to hepatocytes and its relationship to physicochemical properties. Drug Metab Dispos 33:419-425.

Balani SK, Xu X, Pratha V, Koss MA, Amin RD, Dufresne C, Miller RR, Arison BH, Doss GA, Chiba M, et al. (1997) Metabolic profiles of montelukast sodium (Singulair), a potent cysteinyl leukotriene1 receptor antagonist, in human plasma and bile. Drug Metab Dispos 25:1282-1287.

Bushra R and Aslam N (2010) An overview of clinical pharmacology of Ibuprofen. Oman Med J 25:155-1661.

Caldwell J, Staib AH, Cotgreave IA, and Siebert-Weigel M (1986) Theophylline pharmacokinetics after intravenous infusion with ethylenediamine or sodium glycinate. Br J Clin Pharmacol 22 351-355.

Chau NP, Zech PY, Pozet N, and Hadj-Aissa A (1982) Ranitidine kinetics in normal subjects. Clin Pharmacol Ther 31:770-774.

Cheng H, Leff JA, Amin R, Gertz BJ, De Smet M, Noonan N, Rogers JD, Malbecq W, Meisner D, and Somers G (1996) Pharmacokinetics, bioavailability, and safety of montelukast sodium (MK-0476) in healthy males and females. Pharm Res 13:445-448.

Conrad KA and Nyman DW (1980) Effects of metoprolol and propranolol on theophylline elimination. Clin Pharmacol Ther 28:463-467.

Di L, Atkinson K, Orozco CC, Funk C, Zhang H, McDonald TS, Tan B, Lin J, Chang C, and Obach RS (2013) In vitro-in vivo correlation for low-clearance compounds using hepatocyte relay method. Drug Metab Dispos 41:2018-2023.

Di L, Keefer C, Scott DO, Strelevitz TJ, Chang G, Bi Y-A, Lai Y, Duckworth J, Fenner K, Troutman MD, et al. (2012a) Mechanistic insights from comparing intrinsic clearance values between human liver microsomes and hepatocytes to guide drug design. Eur J Med Chem 57: $441-448$.

Di L and Obach RS (2015) Addressing the challenges of low clearance in drug research. AAPS J 17:352-357

Di L, Trapa P, Obach RS, Atkinson K, Bi Y-A, Wolford AC, Tan B, McDonald TS, Lai Y, and Tremaine LM (2012b) A novel relay method for determining low-clearance values. Drug Metab Dispos 40:1860-1865.

Di L, Whitney-Pickett C, Umland JP, Zhang H, Zhang X, Gebhard DF, Lai Y, Federico JJ III, Davidson RE, Smith R, et al. (2011) Development of a new permeability assay using low-efflux MDCKII cells. J Pharm Sci 100:4974-4985.

Dixon R, Gillotin C, Gibbens M, Posner J, and Peck RW (1997) The pharmacokinetics and effects on blood pressure of multiple doses of the novel anti-migraine drug zolmitriptan (311C90) in healthy volunteers. Br J Clin Pharmacol 43:273-281.

Flesch G, Müller P, and Lloyd P (1997) Absolute bioavailability and pharmacokinetics of valsartan, an angiotensin II receptor antagonist, in man. Eur J Clin Pharmacol 52:115-120.

Hallifax D, Foster JA, and Houston JB (2010) Prediction of human metabolic clearance from in vitro systems: retrospective analysis and prospective view. Pharm Res 27:2150-2161.
Hatorp V, Oliver S, and Su CA (1998) Bioavailability of repaglinide, a novel antidiabetic agent, administered orally in tablet or solution form or intravenously in healthy male volunteers. Int $J$ Clin Pharmacol Ther 36:636-641.

Jones HM, Barton HA, Lai Y, Bi YA, Kimoto E, Kempshall S, Tate SC, El-Kattan A, Houston JB, Galetin A, et al. (2012) Mechanistic pharmacokinetic modeling for the prediction of transportermediated disposition in humans from sandwich culture human hepatocyte data. Drug Metab Dispos 40:1007-1017.

Jones HM, Butt RP, Webster RW, Gurrell I, Dzygiel P, Flanagan N, Fraier D, Hay T, Iavarone LE, Luckwell J, et al. (2016) Clinical micro-dose studies to explore the human pharmacokinetics of four selective inhibitors of human Nav1.7 voltage-dependent sodium channels. Clin Pharmacokinet $\mathbf{5 5} \cdot 875-887$.

Kalliokoski A and Niemi M (2009) Impact of OATP transporters on pharmacokinetics. $\mathrm{Br} J$ Pharmacol 158:693-705.

Kilford PJ, Stringer R, Sohal B, Houston JB, and Galetin A (2009) Prediction of drug clearance by glucuronidation from in vitro data: use of combined cytochrome P450 and UDPglucuronosyltransferase cofactors in alamethicin-activated human liver microsomes. Drug Metab Dispos 37:82-89.

Lennernäs H (2003) Clinical pharmacokinetics of atorvastatin. Clin Pharmacokinet 42:1141-1160.

Li R, Barton HA, and Varma MV (2014a) Prediction of pharmacokinetics and drug-drug interactions when hepatic transporters are involved. Clin Pharmacokinet 53:659-678.

Li R, Barton HA, Yates PD, Ghosh A, Wolford AC, Riccardi KA, and Maurer TS (2014b) A "middle-out" approach to human pharmacokinetic predictions for OATP substrates using physiologically-based pharmacokinetic modeling. J Pharmacokinet Pharmacodyn 41:197-209.

Li R, Bi Y-A, Lai Y, Sugano K, Steyn SJ, Trapa PE, and Di L (2014c) Permeability comparison between hepatocyte and low efflux MDCKII cell monolayer. AAPS J 16:802-809.

Lima JJ, Haughey DB, and Leier CV (1984) Disopyramide pharmacokinetics and bioavailability following the simultaneous administration of disopyramide and 14C-disopyramide. $J$ Pharmacokinet Biopharm 12:289-313.

Lindahl A, Sandström R, Ungell AL, Abrahamsson B, Knutson TW, Knutson L, and Lennernäs H (1996) Jejunal permeability and hepatic extraction of fluvastatin in humans. Clin Pharmaco Ther 60:493-503.

Lo MW, Goldberg MR, McCrea JB, Lu H, Furtek CI, and Bjornsson TD (1995) Pharmacokinetics of losartan, an angiotensin II receptor antagonist, and its active metabolite EXP3174 in humans. Clin Pharmacol Ther 58:641-649.

Lombardi TP, Bertino JS Jr, Goldberg A, Middleton E Jr, and Slaughter RL (1987) The effects of a beta-2 selective adrenergic agonist and a beta-nonselective antagonist on theophylline clearance. J Clin Pharmacol 27:523-529.

Mao J, Doshi U, Wright M, Hop CECA, Li AP, and Chen Y (2018) Prediction of the pharmacokinetics of pravastatin as an OATP substrate using plateable human hepatocytes with human plasma data and PBPK modeling. CPT Pharmacometrics Syst Pharmacol 7: 251-258.

Martin PD, Warwick MJ, Dane AL, Brindley C, and Short T (2003) Absolute oral bioavailability of rosuvastatin in healthy white adult male volunteers. Clin Ther 25:2553-2563.

McGourty JC, Silas JH, Fleming JJ, McBurney A, and Ward JW (1985) Pharmacokinetics and beta-blocking effects of timolol in poor and extensive metabolizers of debrisoquin. Clin Pharmacol Ther 38:409-413.

Miyauchi S, Masuda M, Kim S-J, Tanaka Y, Lee K-R, Iwakado S, Nemoto M, Sasaki S, Shimono $\mathrm{K}$, Tanaka Y, et al. (2018) The phenomenon of albumin-mediated hepatic uptake of organic anion transport polypeptide substrates: prediction of the in vivo uptake clearance from the in vitro uptake by isolated hepatocytes using a facilitated-dissociation model. Drug Metab Dispos 46:259-267.

Mück W (2000) Clinical pharmacokinetics of cerivastatin. Clin Pharmacokinet 39:99-116.

Mück W, Ritter W, Ochmann K, Unger S, Ahr G, Wingender W, and Kuhlmann J (1997) Absolute and relative bioavailability of the HMG-CoA reductase inhibitor cerivastatin. Int J Clin Pharmacol Ther 35:255-260.

NDA-019211. (2009) Labels. US Food and Drug Administration. https://www.accessdata.fda.gov/ drugsatfda_docs/label/2009/019211s042lbl.pdf.

NDA-020741. (2017) Labels. US Food and Drug Administration. https://www.accessdata.fda.gov/ drugsatfda_docs/label/2017/020741s041s042lbl.pdf.

NDA-022363. (2009) Clinical pharmacology and biopharmaceutics review. US Food and Drug Administration. https://www.accessdata.fda.gov/drugsatfda_docs/nda/2009/ 022363s000_ClinPharmR_P1.pdf.

NDA-207238. (2017) Labels. US Food and Drug Administration. https://www.accessdata.fda.gov/ drugsatfda_docs/label/2017/207238ORig1s000lbl.pdf.

Neugebauer G, Betzien G, Hrstka V, Kaufmann B, von Möllendorff E, and Abshagen U (1985) Absolute bioavailability and bioequivalence of glibenclamide (Semi-Euglucon N). Int J Clin Pharmacol Ther Toxicol 23:453-460.

Ostenfeld T, Beaumont C, Bullman J, Beaumont M, and Jeffrey P (2012) Human microdose evaluation of the novel EP1 receptor antagonist GSK269984A. Br J Clin Pharmacol 74: 1033-1044.

Pavliv L, Voss B, and Rock A (2011) Pharmacokinetics, safety, and tolerability of a rapid infusion of i.v. ibuprofen in healthy adults. Am J Health Syst Pharm 68:47-51.

Pentikäinen PJ, Neuvonen PJ, and Penttilä A (1983) Pharmacokinetics and pharmacodynamics of glipizide in healthy volunteers. Int J Clin Pharmacol Ther Toxicol 21:98-107.

Riccardi K, Cawley S, Yates PD, Chang C, Funk C, Niosi M, Lin J, and Di L (2015) Plasma protein binding of challenging compounds. J Pharm Sci 104:2627-2636.

Riccardi K, Li Z, Brown JA, Gorgoglione MF, Niosi M, Gosset J, Huard K, Erion DM, and Di L (2016) Determination of unbound partition coefficient and in vitro-in vivo extrapolation for SLC13A transporter-mediated uptake. Drug Metab Dispos 44:1633-1642.

Riccardi K, Lin J, Li Z, Niosi M, Ryu S, Hua W, Atkinson K, Kosa RE, Litchfield J, and Di L (2017) Novel method to predict in vivo liver-to-plasma Kpuu for OATP substrates using suspension hepatocytes. Drug Metab Dispos 45:576-580.

Schmid J, Busch U, Heinzel G, Bozler G, Kaschke S, and Kummer M (1995) Pharmacokinetics and metabolic pattern after intravenous infusion and oral administration to healthy subjects. Drug Metab Dispos 23:1206-1213.

Scott J and Poffenbarger PL (1979) Pharmacogenetics of tolbutamide metabolism in humans. Diabetes 28:41-51.

Seaber EJ, Peck RW, Smith DA, Allanson J, Hefting NR, van Lier JJ, Sollie FA, Wemer J, and Jonkman JH (1998) The absolute bioavailability and effect of food on the pharmacokinetics of zolmitriptan in healthy volunteers. Br J Clin Pharmacol 46:433-439. 
Shalaeva M, Kenseth J, Lombardo F, and Bastin A (2008) Measurement of dissociation constants (pKa values) of organic compounds by multiplexed capillary electrophoresis using aqueous and cosolvent buffers. J Pharm Sci 97:2581-2606.

Shen Z, Rowlings C, Kerr B, Hingorani V, Manhard K, Quart B, Yeh LT, and Storgard C (2015) Pharmacokinetics, pharmacodynamics, and safety of lesinurad, a selective uric acid reabsorption inhibitor, in healthy adult males. Drug Des Devel Ther 9:3423-3434.

Singhvi SM, Pan HY, Morrison RA, and Willard DA (1990) Disposition of pravastatin sodium, a tissue-selective HMG-CoA reductase inhibitor, in healthy subjects. Br J Clin Pharmacol 29: 239-243.

Smith DA, Di L, and Kerns EH (2010) The effect of plasma protein binding on in vivo efficacy: misconceptions in drug discovery. Nat Rev Drug Discov 9:929-939.

Stangier J, Schmid J, Türck D, Switek H, Verhagen A, Peeters PA, van Marle SP, Tamminga WJ, Sollie FA, and Jonkman JH (2000a) Absorption, metabolism, and excretion of intravenously and orally administered [14C]telmisartan in healthy volunteers. J Clin Pharmacol 40:1312-1322.

Stangier J, Su CA, and Roth W (2000b) Pharmacokinetics of orally and intravenously administered telmisartan in healthy young and elderly volunteers and in hypertensive patients. J Int Med Res 28:149-167.

Tsao SC, Sugiyama Y, Sawada Y, Iga T, and Hanano M (1988) Kinetic analysis of albuminmediated uptake of warfarin by perfused rat liver. J Pharmacokinet Biopharm 16:165-181.

Tse FL, Jaffe JM, and Troendle A (1992) Pharmacokinetics of fluvastatin after single and multiple doses in normal volunteers. J Clin Pharmacol 32:630-638.

Vachharajani NN, Shyu WC, Chando TJ, Everett DW, Greene DS, and Barbhaiya RH (1998) Oral bioavailability and disposition characteristics of irbesartan, an angiotensin antagonist, in healthy volunteers. J Clin Pharmacol 38:702-707.

van Hecken AM, Tjandramaga TB, Mullie A, Verbesselt R, and de Schepper PJ (1982) Ranitidine: single dose pharmacokinetics and absolute bioavailability in man. Br J Clin Pharmacol 14: 195-200.
Varma MV, Feng B, Obach RS, Troutman MD, Chupka J, Miller HR, and El-Kattan A (2009) Physicochemical determinants of human renal clearance. J Med Chem 52:4844-4852.

Varma MV, Steyn SJ, Allerton C, and El-Kattan AF (2015) Predicting clearance mechanism in drug discovery: extended clearance classification system (ECCS). Pharm Res 32:3785-3802.

Vestal RE, Thummel KE, Mercer GD, and Koup JR (1986) Comparison of single and multiple dose pharmacokinetics of theophylline using stable isotopes. Eur J Clin Pharmacol 30:113-120.

Weaver ML, Orwig BA, Rodriguez LC, Graham ED, Chin JA, Shapiro MJ, McLeod JF, and Mangold JB (2001) Pharmacokinetics and metabolism of nateglinide in humans. Drug Metab Dispos 29:415-421.

Weber C, Schmitt R, Birnboeck H, Hopfgartner G, van Marle SP, Peeters PA, Jonkman JH, and Jones CR (1996) Pharmacokinetics and pharmacodynamics of the endothelin-receptor antagonist bosentan in healthy human subjects. Clin Pharmacol Ther 60:124-137.

Willis JV, Kendall MJ, Flinn RM, Thornhill DP, and Welling PG (1979) The pharmacokinetics of diclofenac sodium following intravenous and oral administration. Eur J Clin Pharmacol 16 405-410.

Wilson TW, Firor WB, Johnson GE, Holmes GI, Tsianco MC, Huber PB, and Davies RO (1982) Timolol and propranolol: bioavailability, plasma concentrations, and beta blockade. Clin Pharmacol Ther 32:676-685.

Address correspondence to: Dr. $\mathrm{Li} \mathrm{Di}$, Pharmacokinetics, Dynamics and Metabolism, Medicine Design, Pfizer Worldwide R\&D, Groton, CT 06340. E-mail: Li.Di@pfizer.com; or Dr. Rui Li, Systems Modeling and Simulation, Medicine Design, Pfizer Worldwide R\&D, Cambridge, MA 02139. E-mail: Rui.Li5@pfizer.com 